Communication breakdown: How conflict can promote responsible leadership in students

Rupert Higham

Faculty of Education, University of Cambridge, Cambridge, UK

Dr Rupert Higham ${ }^{1}$, Faculty of Education, 184 Hills Road, Cambridge CB2 8PQ, UK

${ }^{1}$ Email: rjeh2@cam.ac.uk 


\title{
Communication breakdown: How conflict can promote responsible leadership in students
}

\begin{abstract}
This study of an outdoor-based leadership course for teenagers shows how open-ended, difficult group tasks can enable participants to develop 'dispositions for learning', which promote 'responsible leadership'. The latter is defined as responding ethically and uniquely to encounters with difference. Uses of educational psychology often circumscribe 'challenge' to avoid risk and promote predictability; a riskier, wilder conception is proposed instead through a 'pedagogy of challenge'. It is shown that course participants reflected on their most difficult moments, most of which ended in failure and dispute, as their most powerful and memorable learning experiences. Implications for schools and classrooms are considered.
\end{abstract}

Keywords: responsible leadership, dispositions for learning, pedagogy of challenge, failure, conflict, dissonance

\section{Introduction: the story so far}

This article builds on work previously published in this journal (Higham, Wegerif, and Freathy 2010), which developed a theoretical model for developing 'responsible leadership' through studying a school-based, two-day indoor leadership education course for a select group of 13 to 18-year-olds. A brief summary of its theoretical framework is given below as background to the present, larger study, which tests that model in a very different context: a five-day residential outdoor education course in leadership for 16-18 year-olds classified at 'NEETs' (Not in Education, Employment or Training). Despite these differences, the findings refine and largely support the model (see Figure 1, p.x); however, this study's location outside the environment and achievement framework of schools gives it a distinct focus on student leadership in relation to personal development and agency. I revisit the concept of a 'pedagogy of challenge' (Higham, Wegerif, and Freathy 2010, 423) in light of this study, arguing that certain psychological theories that have been influential in education, (i.e. Dweck 2000; Czikszentmihalyi 1997; Bandura 1977), have helped promote 'challenge' in learning as valuable, but also as bounded by predetermined outcomes and set at a 'right level' of difficulty. By contrast, this study suggests that open-ended challenges, without direct support, that strongly test teenagers can build the dispositions for learning that underlie responsible leadership - even when the activities involved appear to end in failure and personal conflict.

As the reported study was extensive, only a limited selection of evidence is presented here; other evidence relating to participants' understanding of different leadership roles, motivation and confidence would all have been broadly relevant. The focus of this argument, however, is solely on the link between challenge, conflict and responsible leadership. If such incidents are valuable in developing leadership skills, how might they inform school-based practice? 


\section{Theoretical Framework}

\section{Responsible Leadership}

The term 'responsible leadership' highlights a belief in the central role of dialogue in developing the capacity to lead. Leadership is here understood as: the exercise of agency (see Frost 2006), with and among others, in pursuit of valued ends, in a way that respects the perspectives and upholds the agency of all. To this end, it draws on the egalitarian focus of distributed leadership which highlights the capacity of all to exercise leadership with respect to their individual skills and characteristics (Spillane 2004), as appropriate to an educational context. In these 'safe and confidential settings' (Bolden et al. 2005, 18) stakes are low enough for failure to be edifying rather than traumatising or widely consequential, and no student is granted formal authority over others - only the chance to exercise the influence they gain through building trust. However, distributed leadership remains a predominantly technical term, not a normative one, since it focuses on promoting decision-making processes that can be subverted to undermine egalitarianism (Hatcher 2005; Woods and Gronn 2009). Thus 'responsible leadership' also draws on 'authentic leadership' - specifically, its normative focus on good outcomes that result from genuine expressions of leaders' values put into action (Avolio and Gardner 2005). This theory is particularly appropriate in an educational context for its focus on individuals' self-actualisation through leading: for students, the lessons learned from trying to put one's values into action are ultimately more important than their short-term effect on others.

The final ingredient of 'responsible leadership' is an insight from dialogic and existentialist theories: that authentic action does not reveal some pre-existing and underlying self, but that it is a form of 'coming into the world' (Biesta 2006, 150) in response to the challenge of difference, or 'the otherness of the Other' (ibid.). Agency thus consists of our unique responses to the differing perspectives of others (Wegerif 2011) and the affordances and challenges of our environment (Dewey 1966, 11). Responsible leadership, then, sets a high standard: it is 'not about people doing what they want do to, but about doing what's there to be done' (Higham, Freathy, and Wegerif 2011, 422. Italics in original) as unique, situated and values-informed responses to the challenge of encountering difference. Primarily, it is based on the exercise of influence (understood as dialogic, responsive) as distinct from power (understood as monologic, directive), that seeks to preserve the agency of all parties (Beauvais and Higham 2016).

\section{Dispositions for learning}

Students must be 'ready and willing to take educational opportunities, as well as able' (Carr and Claxton 2002, 10); yet schools focus mostly on students' 'ability' in tightly defined academic contexts, relying on extrinsic factors such as discipline, streaming and summative testing, and on like-for-like preparation for examinations (Perkins and Tishman 2001). This learning tends to be shallow and brittle; subsequently, students often lack the readiness to recognise relevant situations to apply their knowledge and the willingness to do so (ibid.). In response many have tried to develop lists of desirable 
habits of mind, or dispositions for learning, to address this lack (Coffield 2002); for example, Claxton's classification of 'resilience, resourcefulness, reciprocity and reflection' has gained significant influence through the 'Building Learning Power' programme (Claxton et al. 2011).

In the field of leadership education dispositions for learning, however defined, are widely regarded as more valuable in developing leadership capacity than subjectspecific knowledge (Gosling 2004, 3; Swaffield and MacBeath 2009). Successful leadership courses instead promote leadership development through practical action and reflection within learning communities (Bolden et al. 2005; Eich 2008). Here it is proposed that the root of all dispositions for learning is openness: 'a propensity to remove, and continually reject, both self- and socio-culturally imposed limits on responding to the Other' (Higham, Wegerif, and Freathy 2010, 423) - and that any further categorisation stems from this root.

\section{A pedagogy of challenge}

The theoretical framework proposed here (Higham, Wegerif, and Freathy 2010, 423) further draws on Biesta's 'pedagogy of interruption' (Biesta 2006). This emphasises the responsibility of the teacher to disrupt the thinking of students by presenting them with alternative perspectives that they must struggle to understand, and then accommodate or thoughtfully reject. Biesta argues that this is often uncomfortable and unavoidably personal. Education 'ceases to be a process of giving, and instead becomes a process of asking difficult questions' (ibid., 85); the discomfort of that process is both provoked and mitigated within a teacher-student relationship that is primarily an ethical one. The proposed pedagogy of challenge builds on this though advocating that students can be given opportunities to work together on activities that are open-ended, extended and challenging - socially, intellectually, practically, or physically - rather than the onus being on the teacher to 'interrupt' the learner, the environment, task and interaction between students are designed to do this. In this model, active teacher input, if any, comes retrospectively through reflective discussion; the teacher merely creates and holds the activity space, and ensures baseline physical and emotional safety. This is a way of working familiar to outdoor education practitioners.

\section{Untaming 'challenge'}

Rhetorical commitment to the idea of challenge in education is ubiquitous; it is increasingly used as a euphemism for difficulty, suggesting that it is something to relish. Dweck's work on mastery-orientation (2000), and more popularly, 'learning mindsets' (2006), has had a profound impact in questioning and addressing deeply-ingrained concepts of fixed intelligence: it helps both to explain and address the fragility of selfesteem of many learners when faced with problems they can't immediately solve, and provides strong evidence that seeing difficulty as a chance to learn and grow raises selfesteem and attainment. The type of academic educational context Dweck focused on, however, mirrors the more widely popular uses of 'challenge' in referring to reaching pre-defined goals that validate the effort expended: finding the right answer, getting 
better test scores etc. Challenge in this sense refers to bridging the gap between what students currently can do and what they want or need to do.

Similarly, Czikszentmihalyi's theory of optimal experience (1997) argues that learning is best enabled when students are presented with the right level of challenge: ensuring that the activity engages them and holds them in a state of 'flow', which balances skill and challenge evenly to avoid relaxation on the one hand (insufficient challenge) and anxiety on the other (insufficient skill). This requires careful management of learning activities by teachers, similar to the calculated ratcheting up of difficulty of a computer game as players' competence increases. The nature of the sensation of engagement spurs intrinsic motivation, thus continued engagement.

Finally, Bandura's theory of self-efficacy, quickly and widely influential in education after its release (see Multon, Brown, and Lent 1991), posits that an individual's 'conviction that one can successfully execute the behaviour required to produce the outcomes' (Bandura 1977, 193) is crucial in achieving set goals; supporting this development builds over time students' ability to persevere with challenging academic tasks: 'Students who develop a strong sense of self-efficacy are well equipped to educate themselves when they have to rely on their own initiative' (Bandura 1986, 417).

All these models have merit in relation to securing high performance in fixed curricula; from the perspective of a pedagogy of challenge, Dweck's and Bandura's in particular support the proposal that difficulty is an inherent feature of much valuable learning. However, all three have in common a belief that the satisfying experience of achieving identified goals promotes the ability to achieve greater goals in the future, and that this happens at the level of the individual. It is a scaffolded conception that fits neatly into the theory of the Zone of Proximal Development (Vygotsky 1978): challenge becomes understood only within an ordered, time-limited framework in which students take the next logical step in their learning with expert assistance, resources or task design. In short, it is challenge tamed (Perkins 2004). The argument of this paper is that such a careful, incremental approach to building dispositions for learning may not be adequate; that scaffolding may at times constrict development; and that genuine and sustained feelings of fear, uncertainty, frustration, humiliation, anger and despondency may have a part to play - as may prolonged self-examination and occasional exhilaration - in developing desirable dispositions. To experience these, challenge must be released, at times, back into the wild. This is especially the case for teenagers, who are likely to be having many such experiences outside the formal curriculum within and outside school, but without support. Learning to manage such experiences and develop through them, I suggest, develops leadership capacities. This is difficult in a competitive educational climate where task-specific failure is often conflated with the personal label of 'failure', thus understandably seen as damaging to self-esteem (Cigman 2001;

O’Donnell 2014).

\section{Valuing conflict}


This study focuses on group challenges in non-academic contexts where the difficulty springs less from the lack of relevant factual knowledge, and more from the tensions between people's different ideas, attitudes and personalities - and their inability to reconcile them in pursuit of a shared goal. Furthermore there are the added difficulties of not knowing what aspects of one's prior knowledge and experience might be relevant, and of finding the motivation to act in novel ways in alien surroundings. In terms of leadership theory, this reflects the distinction whereby management is understood as optimisation within known parameters, and leadership is about collectively addressing unknowns to find innovative beneficial solutions (Bolden 2004); in educational terms, it reflects the distinction in the aims of school education between high achievement and personal development. A pedagogy of challenge in this context deliberately promotes engagement with inter- and intra-personal conflict without predetermined parameters for success, in terms of either outcome or timescale. Its aim is to help students recognise - often through failure - the limitations of their current skills and understandings, and thus to be motivated to develop them. It builds on Howe's substantial work showing that students, on encountering difficulties in group tasks in science, can be shown to have developed their understanding of the topic some weeks later having not reached a final understanding or agreement at the time. The 'unresolved contradictions' (Howe 2009, 220) experienced in response to the failure to comprehend ideas fully and complete tasks correctly drives students, consciously or unconsciously, to resolve that contradiction through reflection and in future relevantly similar situations (ibid., 221). The premise here is that this process within subject-based learning can be applied to the development of dispositions for learning. Extra-curricular outdoor courses in student leadership like the one presented in this study present good opportunities to explore this possibility.

\section{Research design}

The course studied was a 5-day residential for 10 teenagers ( 7 male, 3 female) aged 1618 on Dartmoor, a wilderness area of South West England. It in turn was one of the first elements of a longer, 3-month Prince's Trust course, designed for those having left education at 16 and unsure of their future direction. Its purpose was to build selfconfidence, teamwork skills, and to help students to find future training and work. The 5-day residential, however, was very similar to many types of team-building used in leadership development: raft-building, orienteering and other similar activities. In addition, the young people were given responsibility for budgeting, cooking, cleaning, navigating and timekeeping for the week - which represented a significant challenge in its own right.

All participants were interviewed before and immediately after the residential course, then again three months later. Three months was chosen as optimally balancing time for dispositions to embed against the rapid development and range of experiences of young people at that stage of life, which makes attribution of attitudinal and behavioural change to specific experiences progressively more difficult. All interviews were semi-structured; questions were similar at all three stages to aid comparison over 
time. Drawing on critical incident recall techniques (Tripp 1993), the first question in each interview asked them to recall moments where 'they felt they'd really learned something' during the previous year (first interview), the residential course (second) and in the previous three months (third). The course leader was interviewed at the second and third stages also. Interviews were transcribed and coded through several iterative cycles using NVivo software. A balance was struck between theory-led and data-led coding (Creswell 2007, 2:66), both reflecting the researcher's theoretical framework and keeping open the possibility of surprising findings - as in the case of 'arguments' reported below. Finally, I took observational notes while attending the 5day course in its entirety in the role of participant/assistant/observer.

The issue of studying a 5-day course embedded within a 3-month course was a confounding factor, since there was the possibility that dispositional change over time following the course might be confused with change arising more quickly in relation to subsequent activities. To mitigate this, I encouraged participants to draw specific links where possible between their choices of particularly significant activities and moments on the course and subsequent changes in behaviour and attitude.

For the purpose of this article, the question used to interrogate the dataset was as follows:

What were the participants' recollections and understandings of challenge and conflict on the residential leadership course, and how did these change over time?

\section{Findings}

Seven overarching themes emerged from the original analysis: challenge and difference; arguments, conflict and conciliation; relating to others; leading and decision-making; following, abstaining and dissenting; identity and motivation; confidence and the future. Findings here draw principally from the first two themes. The theme of 'arguments, conflict and conciliation' was entirely data-led - nothing in my questions or theoretical approach encouraged its emergence, unlike the theme of 'challenge and difference', which was built into the theoretical and methodological frameworks. Names given below are pseudonyms.

\section{Participants' experiences of challenge and conflict}

Participants described several sources of challenging experience, principally: the alien environment and being away from home; social tensions; and the outdoor activities themselves.

\section{Alien environment}

This was compounded for some by the fact that they had rarely left their home city (in George's case, never), let alone gone onto the moor:

I: So how do you feel about the course that's coming up in a couple of weeks - the residential up on Dartmoor?

George: Well, erm... I wouldn't mind it, it's just that I don't like going away from all my family and friends and that too long. I've never really liked going away for a week with new people I haven't met. 
Holly: Erm... kind of nervous because I don't really like staying away from home, but again that'll help me doing stuff like when it come to me living on my own in the future.

Despite their fears, it is interesting that Holly was already making the link between the experience of the course and the upcoming experience of leaving home - an openended, unstructured challenge of the sort that is definitive in our non-academic lives and is seen as part of reaching maturity. Stepping out of the home and school environments also removes them from their strong cultural associations and projected self-images associated with those places; it makes them more open to new experiences as well as more anxious and vulnerable. For Martin and Kat, the limited phone signal in the Dartmoor house was, at least at first, deeply unsettling; for the first two days they explored the area obsessively looking for the one bar of signal that would enable text communication with friends and family. The break in those lines of communication seemed to threaten their identity. However, in the second and third rounds of interviews, not one participant suggested that their fears had been justified. Even Martin, in line with the rest of the group, seemed later to have responded well to the change in surroundings. Asked what he had enjoyed about the course, he replied:

Martin: ... in the house when we all like... socialised together, done stuff, mixed with each other and stuff.

I: How was it without a TV, or radio or Xbox or anything like that?

Martin: Oh, it was alright, because there were loads of us all just having a laugh and that.

Martin, along with three other boys, were self-identified nightly players of online combat games at home; however, he and three other participants cited playing traditional board games in the evenings as the most enjoyable feature of the week. He put particular emphasis on the bonding nature of the activities in what was a very diverse group of teenagers who knew each other little. This enjoyment and socialisation with those they didn't know well, in an environment very different to those there were used to, is evidence of a positive response to a radical break from their usual routines and self-images. It was an environment in which students responded to the demand to break their habits of thought and activity to think and respond differently; it promoted openness.

\section{Social Tensions}

While participants enjoyed much of their shared communal time, the changes in routine (up at $7 \mathrm{am}$, in bed by $11 \mathrm{pm}$, for example) and their responsibilities led to significant tensions - particularly the breakfast rota, which led to the incident Dan described as the most powerful on the course in his second interview:

Dan: It was the morning when somebody was supposed to be cooking breakfast but they didn't get up, so I decided to do it, and I just helped... that morning, I don't know 
what happened but I just felt I was more determined in tasks, just able and focused. And also, because people were kind of helping me as well I just felt more confident around in the kitchen because before I've never really had a chance to do anything in that sense....

$I:$... and has that has made a difference since? You say you've been cooking at home more.

Dan: Yeah. And it's just made me more independent, I suppose - just being able to... know how to do things.

Dan made this move in an atmosphere of mounting tension and hostility in the social area. However, rather than mirroring the predictable reaction of others - getting angry with those whose job it was - his decision to cooking breakfast when it wasn't his turn became a watershed moment personally and socially. The alien environment reduced the social stigma of doing a chore he didn't have to do, and as someone who usually took the back seat in group activities, this was an empowering response to a challenging situation. Dan made the link between his actions and wider independence and confidence in his life subsequently. This fits well with the model of development of responsible leadership in Figure 1 (p.x).

Some social situations, however, reached boiling point. On the penultimate afternoon, after an activity that went badly and ended in recrimination within and between two teams, one participant noticed that Holly - a quirky, shy girl - didn't have her seatbelt on in the minibus home. He let her know in highly derogatory and sexist language. Holly's response was an absolute lockdown: she refused to speak, refused to move, refused to do up her seatbelt. We couldn't move. There were over 10 minutes of heated exchanges, both aggressive towards and supportive of Holly. The course leader watched attentively, but took no action other than to confirm that we could not move until all had their seatbelts fastened. Eventually, she silently consented to another participant's offer to put her seatbelt on for her. On reaching the house, Holly went to her room and the rest discussed events. Differences were aired, but no conclusion reached. Several threatened to take no part in the final day's activities. On the face of it this was a teacher's nightmare: a social disaster and a risk to personal safety. However, the participants' recollections of it in the second interview were remarkable:

I: You enjoyed the whole thing?

Kat: Apart from the arguments.

I: How do you feel about those? Were they necessary, or not?

Kat: Yeah, cause if we didn't have arguments we wouldn't have got as far as we did in the end.

I: OK - so you didn't enjoy them but you thought they were useful?

Kat: Yeah, cause everyone got everything off their chest, and everything actually come out and, like, people started to change...

I: That's interesting. Can you think of any examples of that?

Kat: Like when it happened with Holly. She actually said, like, what she felt on the minibus... and then... $X$ and that lot stopped picking on her, really. They stopped picking on her and stopped acting so immature.

I: OK. So even though that was something you didn't enjoy, you thought it was 
something valuable for the group.

Kat: Yeah, for everyone.

The final day's activities did take place, and went far better than any previously. The participants' anger following their discussions dissipated slowly as they cooked a roast dinner, chopped wood for the fire, and played hacky-sack. Holly, who appeared to recover during the evening and took a full part in the next day's activities, later looked back at the moments of high confrontation positively:

Holly: I didn't really like the arguing so much [laughs].

I: No - nobody does. Do you think there was any point in all of those arguments?

Holly: I don't know really. In fact, I think it probably did, because come to think of it we got all the arguing out of the way, which meant we worked better at the end of it.

This sense of the inevitability of arguments was shared by George and by Jake, who was instrumental in challenging the participants who were aggressive towards Holly. While he struggled to express his insight clearly, I found it profound:

I: Did you spot any times when you felt that those arguments were productive, or at least what came out of it was productive, or not?

Jake: Yeah, because if some people didn't say some stuff they had to... it'd be a bit... it didn't feel... you know... like, some of the trust comes up, people don't like it - that's when you slow down...

I: When the trust... comes up, people don't like it (Jake: yeah.)? You mean when it gets shown that...

Jake: Yeah, that that's what really happening, behind the closed doors.

As I interpret it, Jake believed that arguments can reveal people's prejudice, animosity, and resentment - but also the seeds of truth, the insight into others, that helped form these negative impressions and that they wouldn't normally share. This can lead to volatile but ultimately cathartic situations that can dispel tensions, and lead to opportunities for leadership, personal development and a shared sense of trust and solidarity. Such situations are risky, and good outcomes cannot be guaranteed, yet the unanimity of participants' opinions on the lasting and wide-reaching benefits of these arguments was striking - all the more so since the course leader described this group during the course as one of the most fractious and dysfunctional he had taught in his years of experience. By the time of the third interview three months later, participants played down the arguments, focusing instead on the sense of solidarity their experiences had built:

Steve: ... we all had tiffs, we've all got over it, and worked as a team... we've had problems, we've all spoken it out... we've had job problems, we've all spoken, sussed it out, and got sorted out....

Steve was particularly positive about the group's activities and inclined to make light of its difficulties. He gives the impression here that the disputes were overtly resolved, yet they were not - at least, according to the course leader. Steve's remarks support the 
hypothesis that unresolved conflicts may resolve tacitly over time through selfreflection and the response to future relevant situations, especially if trust has been built. It is interesting that he talks about the same attitude in relation to their subsequent work experience ('job problems') later in the Prince's Trust course; it suggests a transfer of skills and continuing sense of solidarity in relation to problems on their different work places. However, three participants, Steve, George and Dan, explicitly hedged this by saying that they didn't know whether what they'd learned would apply elsewhere, outside the group and course. For some, I suggest, the course became a bubble in which they came to feel empowered and safe, while remaining uncertain about accepting this as lasting dispositional change. The alien environment that made them more open to difference did not, for some, easily link back to the familiar world of their everyday lives. For them one such course, or other similar experience, may not be sufficient by itself to overturn attitudes cemented over years - even if they have gained the insight that they can, in favourable circumstances, think and act differently to their prior expectations of themselves.

\section{Outdoor activities}

In the second round of interviews, the two abseiling activities were recalled by most as the activities they had found most challenging. For Carla, it was the opportunity to confront a personal fear:

Carla: I thought it (abseiling) was really good.

I: What was it - the height, or?

Carla: Because I overcame my fear of heights.

I: Did it? Did you have a fear of heights?

Carla: Yeah, only a little bit of a fear of heights.

I: I thought the most difficult bit was... getting over the rail was a bit weird, wasn't it

(Carla: mmm, yeah), and then the bit when you got to the bottom of the bricks...

Carla: Yeah, and you had to let your feet go.

I: And why do you remember that moment particularly as number one?

Carla: Because it was... the best part of the whole week!

The power of outdoor education activities to help people overcome specific fears through communal activity is well known, as is the sense of exhilaration and increased confidence (albeit relatively context-limited) that can come with it. Abseiling can be particularly challenging for people who find it hard to trust others, as they must put their life in the hands of instructors and the equipment. In the case of the second abseiling activity, while participants were overseen by staff, they had to set up the equipment, check it and operate it as a group. This activity was quite fractious and caused some anxiety, as Kat described in her second interview:

I: Were there any particular parts of the course that really made you want to try hard? Kat: In the beginning, like, the rock climbing - when we abseiled off the rock face like, not everyone wanted to do it, and me and Carla were listening, and we had to lower two more people down, and like, there was someone skipping [with the rope] 
with the rest of them refusing to listen, and I just went that 'you can all work together in the end'.

I: That's interesting - so the thing that motivated you was a moment when other people were a bit scared or in need of support (Kat: yeah) and you stepped in when others weren't (Kat: yeah), cause you wanted to help the others out.

Kat: Yeah. At the end of the day if it was me at the top I wouldn't like it.

The activity was memorable for Kat not because of her own abseil, but because of her choosing to take a coordinating and supporting role; this in turn was motivated by her sympathy towards and desire to help those who were clearly scared - and to rally those who had lost attention and were thus adding to the others' distress. Her final comment above is a clear case of 'putting yourself in someone's shoes': the basis of the ethical relationship that underpins the humane response to difference. Her memory of one of her most important moments was one where a stressful situation was close to going out of control, with disharmony and disregard for each other's feelings and safety. Her response - all the more remarkable since she had previously been uncooperative in group tasks and got into several personal conflicts - demonstrated empathy, selfefficacy and authority. The course leader echoed this in his second interview describing her by the end as:

Leader: ....almost unrecognisable... her level of aggression dropped significantly, her manners improved, her temper improved... she took longer to express her opinion and expressed it more eloquently.

Again, as in the minibus, a highly volatile situation called out the genuine agency of one of the participants in a way they and others subsequently reflected on as significant and valuable; again, challenge and dispute provoked acts of responsible leadership. In Kat's case in particular there is evidence that this contributed to significant and lasting dispositional change.

As mentioned earlier, the final day's activity was markedly more cooperative, and was commented on by all participants as having been satisfying and enjoyable. George recalled one part where one group was required to carry a suddenly 'injured' member (me) over a stream and up a hill to complete the challenge.

I: Anything else where you pushed yourself a bit or did what you didn't think you'd do? George: The final challenge, maybe.

I: How did... where on the final challenge did you push yourself a bit, maybe?

George: Erm... probably when we went to get you up the hill.

I: Yeah, I'm not getting any lighter these days! And did you enjoy it or did it just hurt? George: Erm... it was fun, but it hurt a bit!

I: And how did you feel when everyone was at the top - just in time, wasn't it (George: yeah) - with 5 minutes to go...

George: Relieved that we'd done it all on time.

This was the most physically challenging element of the entire course; George and others overcame considerable discomfort to complete the task. Their behaviour in 
activities in the first three days suggested that they wouldn't have done so prior to the final day. The minibus incident and its aftermath, as suggested above, appears in retrospect to have been a turning point in the group's attitude towards participation in course activities. Back in the house that Thursday evening Jake had spoken about his desire to come away from the course with a sense of achievement by finishing on a high - a sentiment he recalled in his second interview. This resonated strongly with the rest of the group, and palpably changed the mood. Jake had been an Army Cadet and thus was quite experienced in outdoor education. The course leader observed that Jake saw himself as having leadership skills, and that others perceived this also and looked for leadership from him; however, he had often "reverted from being a leader into being a bit of a kind of joker, and a Jack the Lad". His sense that he had demonstrated responsible leadership in this situation was reinforced by his responses in the second interview to a 'diamond 9' activity where he was asked to rank 9 cards, each with a possible leadership skill on it, in order of importance. He was presented with his choice from the first interview, asked whether he wanted to make any changes, and to justify any he made:

I: You've got the listening ones first, and the persuading ones lower down [than in the first interview].

Jake: Yeah, it's best to listen before you start opening your mouth.

I: Do you feel that you did that more on the course, or is that a thought that's come out of it?

Jake: A little bit near the end, yeah. I wouldn't say so at the beginning.

Jake's intervention on the Thursday evening was precisely one of listening first, then persuading - or influencing. His recognition of the primacy of listening was echoed by comments from George, Kat and others. The final interview with the course leader suggested that Jake's realisation led to enduring dispositional change over the next three months:

Leader: ...he's retained that ability to be very immature juvenile at points, but they've become less and less frequent.... He has spent a lot of time making sure that his CV is up to scratch, and really considering where he's going to go after the Prince's Trust course.... he started to understand that his ability exceeded his current level, and that he could do much better if he applied himself.

Jake appeared to have fewer flights from responsibility after the course, joking less and concentrating more - although the greater subsequent focus on personal tasks and responsibilities, like CV writing, are not fully comparable. Together, however, this evidence supports the model of authentic leadership as deriving from openness and responsiveness to challenging situations, rather than the imposition of one's will or ideas.

\section{Discussion}


To begin, it is worth expanding on a finding from the previous study mentioned above. The 2-day indoor leadership course was highly structured with 20-30 minute activities followed by reflective discussion, greatly reducing the possibility for extended conflict and lack of resolution. Despite this, several participants named a role-play activity, in which they had to give a candidate the news that their bid for funds was not successful, as by far the most challenging. Unwilling to present the news straightforwardly, they fell into evasion and verbal aggression, straying far outside their remit of simply relaying the news. In the subsequent interview, participants reported having felt genuine fear despite the artificial situation; they found this particularly valuable in retrospect as it had surprised them and highlighted their weaknesses (Higham, Freathy and Wegerif 2010, p.426).

This study builds substantially on that prior finding, providing further evidence that genuinely challenging situations - to the point of causing anxiety on the part of participants - are often regarded by them subsequently as their most valuable learning experiences, even when those challenges are not directly resolved. In the quotations above, participants' acknowledgement of their own and others' failures, hostility and breakdowns in the face of challenge are central to their narratives of learning and dispositional change. There were no descriptions of problems solved on the spot through negotiation (although some were resolved through unilateral action), and yet the more time passed, the more positive they perceived these experiences to have been. Furthermore, evidence from self-report and from the course leader testified that these experiences led, with caveats around transferability outside the group context, to lasting dispositional change in most participants. This evidence accords with the model for developing responsible leadership in Figure 1. 
Figure 1. Model for the development of student agency through responsible leadership

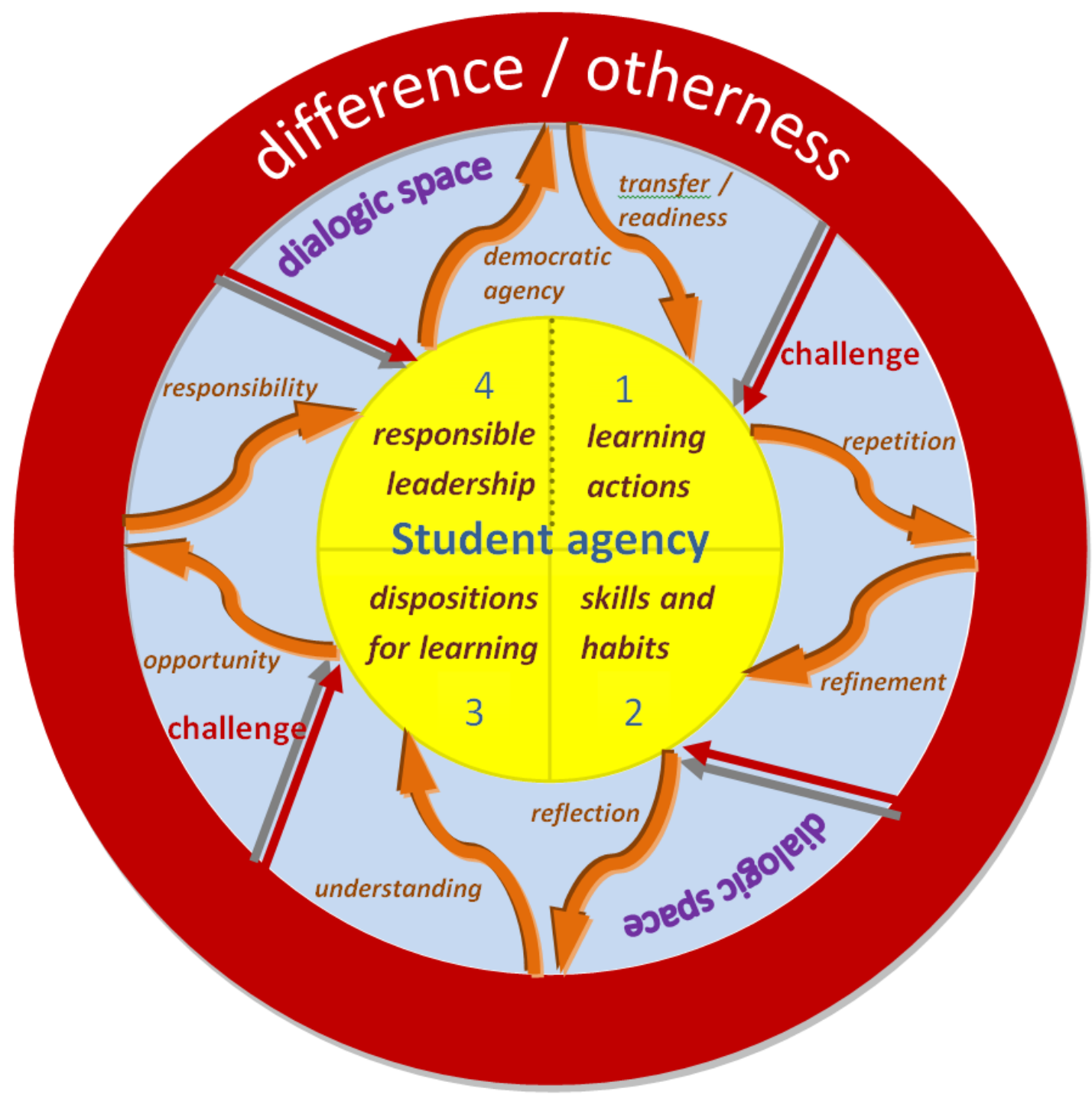

Developing responsible leadership through challenge

These findings prompt a deeper analysis of the relationship between a pedagogy of challenge and leadership development. When participants demonstrated responsible leadership on the course, such as Kat organising the abseiling task or Jake's rallying speech after the minibus incident, these were understood as responses to social and environmental challenges, as doing what needed to be done, rather than doing what you want to do. In relation to Biesta's stipulation that education be 'a process of asking difficult questions' $(2006,85)$, here these were asked by the situation rather than by a teacher; participants' responses were drawn out of them, rather than deliberately chosen, by young people who had stated in interview that they were reluctant to engage in leadership roles. This also lends support to Dewey's and Biesta's analyses that the pedagogical relationship is fundamentally an ethical one: the spur to action in these cases is to respond to the needs of others, physically or emotionally, in a way that reflects one's values. Finally, it accords with Biesta's concept of 'coming into the world' $(2006,150)$ in locating responsible leadership not in the participants' enduring 
traits or common behaviours, but in their authentic responses to difference in challenging circumstances.

This evidence also questions the assumption that students need to be 'ready, willing and able' to learn (Carr and Claxton 2002,10) - at least in some circumstances. Many of the challenging situations described above were ones where participants failed to meet at least one, and possibly all three, of those criteria. Often, dispositional change came about as a result of their subsequent reflection on this personal or collective failure in challenging situations. These findings mirror Howe's (2009) research on the significant delayed impact on learning of challenging learners through dialogue with those who have different perspectives. A pedagogy of challenge, then, can spur subsequent dispositional change; the failure to reach a satisfactory conclusion to a situation that makes more positive responses to future challenging contexts possible, even if the benefits are not immediately apparent.

\section{Compatibility of a classroom pedagogy of challenge with psychological theorisations}

In comparing this course to classroom learning there are significant differences to consider. Here there was time and space for confusion, disagreement and dispute, for cooling off and reflection, and for subsequent negotiation and team-building. The focus was thus on metacognitive learning or personal development rather than on subject content. Also, classrooms are suffused with rules, memories, associations and social structures; stepping outside these gives students a change to present themselves differently and to step outside habituated patterns of behaviour. All this means that both the nature of challenges experienced in these contexts, and the possibilities for response, are very different. I suggest that this highlights important incompatibilities with the three psychological theories discussed earlier.

Firstly, having a 'fixed mindset' (Dweck 2006) may be a less limiting factor in relation to extended, non-assessed, extra-curricular activities; participants on the course displayed brittleness and anxiety in the face of failure, but subsequently recovered and learned from the experience, however unpleasant at the time. Such reflectiveness and resilience in the face of failure are the qualities of a 'learning mindset', albeit over a longer timescale. Such courses and experiences may even offer secure intentional spaces in which the implications of a fixed mindset can be played out to destruction, thus offering participants the chance to recognise its limitations and to change.

Secondly, there was little experience of 'flow' (Czikszentmihalyi 1997) during the course; learning occurred principally through subsequent reflection on a few critical incidents. Anxiety, an unproductive extreme to be avoided in flow theory, was a key factor in precipitating dispositional change. Maintaining participants' continuous engagement with tasks was not critical on the course; rather, fluctuations in their engagement often led to those valuable critical incidents. In its understanding of learning, a pedagogy of challenge is thus more similar to gestalt theory than to the steady, accretional model implied by 'flow' theory. Intrinsic motivation is thereby linked to the drive for self-improvement in the face of challenge and failure, rather than the dopamine hit of achieving a series of successful outcomes.

Finally, a pedagogy of challenge may draw usefully on self-efficacy theory by 
changing one of the premises: by switching the focus from predicting successful outcomes towards understanding learning from difficulty and failure. Self-efficacy, understood as one's belief in one's ability to succeed in the challenge faced (Bandura 1977), helps to explain the dissonance between the senses of 'ideal self' and 'actual self' in the face of failure. Similarly to flow theory, the implications for self-efficacy theory in education are rendered less secure when we principally value not the achievement of desired results, but learning that emerges from the attempt to do so.

\section{Conclusions}

The argument above, supported by a small but detailed and consistent body of evidence, is that a wilder, riskier, more open-ended experience of challenge can promote development in the dispositions for learning that enable responsible leadership. Despite this greater risk and unpredictability, it crucially retains the ethical commitment to students' development that, for Biesta, underpins the pedagogical relationship - it is not a 'sink or swim' approach. If the participants had experienced conflicts like these outside of a course designed to develop leadership skills, it is unlikely that such arguments would have led to the same productive dissonance that spurred their dispositional change.

This argument also suggests that a pedagogy of challenge need not rely directly on the immediate provocation of a teacher, but can be mediated through considered exposure to unfamiliar social and physical environments and tasks. It may have particular relevance, therefore, to adolescents who are leaving formal education for spheres of work and activity where their dispositions for learning, rather than their prior academic attainment, are vital to success. However, my contention is that it is possible to reflect these insights from non-formal leadership education contexts in schools. In the examples above, participants were spurred into responsible leadership in response to challenging situations either out of a sense of ethical necessity in the face of others' distress, or a sense of the opportunities arising to act in new and valued ways. How might study within the curriculum present aspects of the world that generate such a sense of personal relevance and ethical immediacy, and offer the scope to act in response? Also, how might the already challenging social aspects of school life be reconceived as central to learning? One compatible pedagogical approach is the 'Index for Inclusion' (Booth and Ainscow 2016); it encourages schools to offer more openended opportunities through which the barriers between classroom learning and individual, social and global problems are removed; it promotes challenging students to actively engage with different perspectives around these issues, and supporting them in learning from their responses (see EASPD 2012; Booth 2015). This is in line with Dewey's demand that "the formal content of the logical disciplines be 're-clothed' in the experience of learners" (Bonnett 2009, 366).

\section{Acknowledgements}


To Ged Walker, in recognition of his highly skilled management of the course and his generous assistance with this research project.

\section{Bibliography}

Avolio, Bruce J., and William L. Gardner. 2005. "Authentic Leadership Development: Getting to the Root of Positive Forms of Leadership." The Leadership Quarterly 16 (3): 315-38.

Bandura, Albert. 1977. "Self-Efficacy: Toward a Unifying Theory of Behavioral Change." Psychological Review 84 (2): 191-215. doi:10.1037/0033295X.84.2.191.

- 1986. Social Foundations of Thought and Action. Englewood Cliffs, NJ Prentice Hall.

Beauvais, Clémentine, and Rupert Higham. 2016. “A Reappraisal of Children's 'Potential."' Studies in Philosophy and Education, January. doi:10.1007/s11217016-9508-5.

Biesta, Gert. 2006. Beyond Learning: Democratic Education for a Human Future. Boulder, CO: Paradigm Publishers.

Bolden, Richard. 2004. "What Is Leadership?" 1. Exeter: Leadership South West. internal-pdf://Bolden - What is Leadership-0658041857/Bolden - What is Leadership.pdf.

Bolden, Richard, Peter Case, Jonathan Gosling, Alan Hooper, Keith Kinsella, Donna Ladkin, Robin Ladkin, Neville Osrin, and John Potter. 2005a. "What Is Leadership Development?” Exeter: Leadership South West. http://www.iedc.si/programs/seminars/hrmasterclass/photos/What_is_Leadershi p_Development.pdf.

Bonnett, Michael. 2009. "Education and Selfhood: A Phenomenological Investigation." Journal of Philosophy of Education 43 (3): 357-70. doi:10.1111/j.14679752.2009.00698.x.

Booth, Tony. 2015. "Is 'Learning without Limits' a Framework of Values?." FORUM 57 (3): 325. doi:10.15730/forum.2015.57.3.325.

Booth, Tony, and Mel Ainscow. 2016. Index for Inclusion: A Guide to School Development Led by Inclusive Values. 4th Edition. Cambridge, UK: Index for Inclusion.

Carr, Margaret, and Guy Claxton. 2002. "Tracking the Development of Learning Dispositions." Assessment in Education: Principles, Policy \& Practice 9 (1): 937.

Cigman, Ruth. 2001. "Self-Esteem And The Confidence To Fail." Journal of Philosophy of Education 35 (4): 561-76.

Claxton, Guy, Maryl Chambers, Graham Powell, and Bill Lucas. 2011. "The Learning Powered School." Pioneering 21st Centrury Education.

Coffield, Frank. 2002. "Skills for the Future: I've Got a Little List." Assessment in Education: Principles, Policy \& Practice 9 (1): 39-43.

Creswell, John. 2007. Qualitative Inquiry and Research Design: Choosing among Five Approaches. Vol. 2. Thousand Oaks, CA: Sage.

Czikszentmihalyi, Mihalyi. 1997. Finding Flow: The Psychology of Engagement with Everyday Life. New York: Basic Books.

Dewey, John. 1966. Democracy and Education. New York: The Free Press.

Dweck, Carol. 2000. Self-Theories: Their Role in Motivation, Personality, and Development. Philadelphia: Psychology Press. 2006. Mindset: The New Psychology of Success. New York: Ballantine Books. 
Eich, Darin. 2008. “A Grounded Theory of High-Quality Leadership Programs: Perspectives From Student Leadership Development Programs in Higher Education." Journal of Leadership and Organizational Studies 15 (2): 176-87.

Frost, David. 2006. "The Concept of 'Agency' in Leadership for Learning." Leading and Managing 12 (2): 19-28.

Gosling, Jonathan. 2004. "Leadership Development in Management Education." Business Leadership Review. www.mbaworld.com/blrissues/article1.htm.

Hatcher, Richard. 2005. "The Distribution of Leadership and Power in Schools." British Journal of Sociology of Education 26 (2): 253-67.

Higham, Rupert, Rob Freathy, and Rupert Wegerif. n.d. "Developing Responsible Leadership through a 'Pedagogy of Challenge': An Investigation into the Impact of Leadership Education on Teenagers." School Leadership \& Management 30 (5): 419-34.

Howe, Christine. 2009. "Collaborative Group Work in Middle Childhood." Human Development 52 (4): 215-39. doi:10.1159/000215072.

Multon, Karen D., Steven D. Brown, and Robert W. Lent. 1991. "Relation of SelfEfficacy Beliefs to Academic Outcomes: A Meta-Analytic Investigation." Journal of Counseling Psychology 38 (1): 30-38. doi:10.1037/00220167.38.1.30.

O'donnell, Aislinn. 2014. "Another Relationship to Failure: Reflections on Beckett and Education." Journal of Philosophy of Education 48 (2): 260-75.

Perkins, David, and Shari Tishman. 2001. "Dispositional Aspects of Intelligence." In Intelligence and Personality: Bridging the Gap in Theory and Measurement, edited by Janet M. Collis and Samuel Messick. Mahwah, NJ: Lawrence Erlbaum Associates.

Spillane, J. 2004. "Distributed Leadership: What's All the Hoopla?" internalpdf://Spillane - Distributed hoopla-1366881024/Spillane - Distributed hoopla.pdf internal-pdf://Taylor - Consent and inquiry-0009024000/Taylor Consent and inquiry.pdf.

Swaffield, Sue, and John MacBeath. 2009. "Leadership for Learning." In Connecting Leadership and Learning, edited by John MacBeath and Neil Dempster, 32-52. Abingdon, Oxon: Routledge.

Tripp, David. 1993. Critical Incidents in Teaching: Developing Professional Judgement. Abingdon, Oxon: Routledge.

Vygotsky, Lev.S. 1978. Mind in Society: The Development of Higher Psychological Proceses. Cambridge, MA: Harvard University Press.

Wegerif, Rupert. 2011. "Towards a Dialogic Theory of How Children Learn to Think." Thinking Skills and Creativity 6 (3): 179-90.

Woods, Philip, and Peter Gronn. 2009. "Nurturing Democracy." Educational Management Administration \& Leadership 37 (4): 430-51. 